\title{
Premature Closure of Ductus Arteriosus
}

National Cancer Institute

\section{Source}

National Cancer Institute. Premature Closure of Ductus Arteriosus. NCI Thesaurus. Code C99024.

Closure of the ductus arteriosus prior to birth. 